\title{
BMJ Open Exploring medical students' perceptions of the challenges and benefits of volunteering in the intensive care unit during the COVID-19 pandemic: a qualitative study
}

\author{
Aliya Ali, ${ }^{1}$ Marita Staunton, ${ }^{1}$ Adam Quinn, ${ }^{1}$ Gordon Treacy, ${ }^{1}$ Patrick Kennelly, \\ Arnold Hill, ${ }^{2,3}$ Seamus Sreenan, ${ }^{1,4}$ Marian Brennan (D) 1,5
}

To cite: Ali A, Staunton M, Quinn A, et al. Exploring medical students' perceptions of the challenges and benefits of volunteering in the intensive care unit during the COVID-19 pandemic: a qualitative study. BMJ Open 2021;11:e055001. doi:10.1136/ bmjopen-2021-055001

- Prepublication history for this paper is available online. To view these files, please visit the journal online (http://dx.doi. org/10.1136/bmjopen-2021055001).

Received 30 June 2021

Accepted 19 November 2021

Check for updates

(C) Author(s) (or their employer(s)) 2021. Re-use permitted under CC BY-NC. No commercial re-use. See rights and permissions. Published by BMJ.

${ }^{1}$ Graduate Entry Medicine, Royal College of Surgeons in Ireland,

Dublin, Ireland

${ }^{2}$ Department of Surgery, RCSI,

Dublin, Ireland

${ }^{3}$ Department of Surgery, Beaumont Hospital, Dublin, Ireland

${ }^{4}$ Diabetes and

Endocrinology, Connolly

Hospital Blanchardstown,

Blanchardstown, Dublin, Ireland

${ }^{5}$ School of Pharmacy and

Biomedical Sciences, RCSI,

Dublin, Ireland

Correspondence to

Dr Marian Brennan;

mbrennan3@rcsi.com

\section{ABSTRACT}

Objectives In March 2020, the WHO declared SARS-

CoV-2 a pandemic. Hospitals across the world faced staff, bed and supply shortages, with some European hospitals calling on medical students to fill the staffing gaps. This study aimed to document the impact of volunteering during the COVID-19 pandemic on students' professional development, resilience and future perceived career choices.

Design This is a retrospective, qualitative study of student reflections, using purposive sampling.

The Royal College of Surgeons in Ireland (RCSI) University of Medicine and Health Sciences recruited 26 medical student volunteers to assist in pronation and supination of ventilated patients affected by SARS-CoV-2. These students were invited to complete an anonymous survey based on their experiences as volunteers. Thematic analysis was performed on these written reflections. Results The results showed that volunteering during the COVID-19 pandemic developed key skills from RCSI's medical curriculum, significantly fostered medical students' resilience and guided their career choices. Major areas of development included communication, teamwork, compassion and altruism, which are not easily developed through the formal curriculum. A further area that was highlighted was the importance of evidence-based health in a pandemic. Finally, our respondents were early stage medical students with limited clinical exposure. Some found the experience difficult to cope with and therefore supports should be established for students volunteering in such a crisis.

Conclusion These results suggest that clinical exposure is an important driver in developing students' resilience and that volunteering during a pandemic has multiple benefits to students' professional development and professional identity formation.

\section{INTRODUCTION}

The National Public Health Emergency Team confirmed the first case of SARS-CoV-2, in Ireland on 29 February $2020 .{ }^{1}$ Subsequently, the Irish government implemented the
Strengths and limitations of this study

- This study was an anonymous, reflective study focussing on students' perspectives of volunteering, therefore the responses are likely to be uninhibited.

- Our sample size was relatively small.

- Study responses were from early stage medical students in Ireland, therefore the results represent students who had not had significant clinical experience.

closure of Irish schools and universities. With the exponential rise in both cases and intensive care unit (ICU) admissions, consideration was given to the integration of medical student volunteers into Irish hospitals. In March 2020, the Royal College of Surgeons in Ireland (RCSI) reached out to a cohort of students, requesting volunteers for two clinical sites in Dublin.

The utilisation of medical students during public health crises has emerged as a common practice, often consisting of a volunteer recruitment drive followed by training. ${ }^{23}$ This practice of medical student recruitment during pandemics dates as far back as the 1918 Spanish influenza pandemic, when students were educated with one lecture on influenza prior to being sent to field hospitals to treat patients. ${ }^{4}$ During the Copenhagen poliomyelitis epidemic of 1952, volunteer medical students from Denmark were recruited to manually ventilate patients due to rapidly increasing numbers of patients with respiratory paralysis in addition to a mechanical ventilator shortages. ${ }^{2}$ More recently, in the National Health Service (NHS) winter crisis of $2017 / 2018$, a surge in patients with influenza, prompted recruitment of medical students to emergency departments in an 
effort to ease the significant pressures on the healthcare system. ${ }^{5}$

The role of medical students during the SARS-CoV-2 pandemic has included, but is not limited to, provision of childcare for healthcare workers, distribution of personal protective equipment (PPE), engaging in research, laboratory testing, contact tracing and public education. ${ }^{6-9}$ Medical students at Aalborg University in Denmark operated as ventilator therapy assistants and nursing assistants after a brief training course, with $31 \%$ of bachelor students deployed working directly on the frontline across nine pandemic emergency departments. ${ }^{10}$ In excess of 1500 medical students volunteered in Israel to ease the burden on their country's healthcare system. Students were deployed to roles ranging from diagnostic COVID-19 testing in laboratories to telephone support for elderly patients to assess their medical and social needs. ${ }^{7}$

Factors affecting medical students' willingness to volunteer during public health crises prior to COVID-19 show consistencies across geographical locations, and the nature of the pandemic in question. Prior to the COVID-19 pandemic, Canadian medical students highlighted their belief that they have an obligation to volunteer during a pandemic, as it could have the potential to provide valuable training while a large part of the healthcare workforce may be otherwise engaged, or infected and on sick leave. ${ }^{11}$ A large study in Saudi Arabia also found that moral factors were the most important motivators for volunteering. ${ }^{12}$ Professional development and learning opportunities are a recurring prominent factor for medical students when considering volunteering during pandemics. Altruism and professional development represented the highest motivating factors for medical students in a survey completed prior to the emergence of COVID-19. ${ }^{13}{ }^{14}$ Since COVID-19 emerged, studies have shown that large majorities of healthcare students were willing to join the COVID-19 response, citing common drivers such as 'care for fellow human beings', 'pride in contributing', 'shortage of medical personal', 'solicitation by stakeholders' and a 'sense of duty' as motivational factors. ${ }^{1516}$

The risk of contracting and transmitting SARS-CoV-2 plays a large role in medical students' willingness to volunteer, and infecting family members was cited as a major source of stress and concern among healthcare workers in Wuhan. ${ }^{17-19}$ Interestingly, of a cohort of 6700 students triaging and swabbing potentially positive patients, none tested positive for SARS-CoV-2. ${ }^{20}$ Lack of interest, lack of knowledge, personal health issues and transportation issues were identified as further barriers to volunteering in Saudi Arabia. ${ }^{12}$

Previously, common themes observed among volunteers in healthcare settings include high levels of moral distress, interpersonal isolation, barriers created by PPE and student frustration at inability to help in certain circumstances. ${ }^{21}$ Of particular interest to this pandemic, familial concerns, fear of contagion, stresses in the workplace, isolation from others, stigmatisation and additional workload were all listed as significant emotional stressors experienced by healthcare staff during the 2003 SARS outbreak. ${ }^{22-24}$

Literature supporting the existence of psychological supports for healthcare workers, particularly during an outbreak, is sparse. Psychological outcomes following the SARS-CoV-1 epidemic affected nearly $25 \%$ of doctors, including severe emotional distress and a high probability of post-traumatic stress disorder shortly after the situation had resolved..$^{22} 23$ 25-28 A study by Chawlowska et al identified that the volunteering experience was beneficial to students in developing both soft skills and medical skills. ${ }^{29}$ In this study, however, only $38.6 \%$ of student volunteers said they had access to psychological support, and this highlighted the need to support student volunteers.

While there are challenges for student volunteers in a pandemic, there can also be educational benefits that are not easily quantified. We sought to understand the impact of volunteering during the COVID-19 pandemic on medical students' resilience, emotional development and personal growth. Furthermore, we have investigated the influence volunteering has had on student's perception of future career choices.

\section{METHODS}

Between March and May 2020, 26 medical students from RCSI were recruited to volunteer in the ICUs of two affiliated teaching hospitals. Medical students were recruited from the early years of their medical programme (years $1-3)$. Their role was clearly defined as the pronation and supination of ventilated patients suffering from acute respiratory distress syndrome secondary to COVID-19 infections. Students volunteered for 3 months from March to May of 2020.

Purposive sampling was used to recruit the students who had volunteered. Participants then shared their personal reflections via an anonymous survey, using the Microsoft Forms platform. All 26 students who had volunteered were invited to participate in the survey, of whom 13 responded to the survey. There was an intentional time lag of 3 months between the end of medical service and the data collection period in order to allow for internalisation of the proning experience. A gatekeeper was used to recruit participants via email.

The participant information leaflet was distributed to participants prior to receiving the online survey and consent form.

\section{Determination of questions and themes}

Several themes have been documented as prominent motivational factors for medical student volunteering during pandemic situations, including but not limited to professional development, altruism and pride in the ability to contribute. ${ }^{13-1517}$ The questions chosen for this study were chosen in attempt to further explore and develop these themes. Authors built the questions related to professionalism based on RCSI's definition of professionalism 
Table 1 Reflection questions used in the online questionnaire

\begin{tabular}{|c|c|}
\hline & Question \\
\hline 1. & $\begin{array}{l}\text { How did you decide to volunteer for the proning } \\
\text { team? }\end{array}$ \\
\hline 2. & How did this decision affect your life at home? \\
\hline 3. & $\begin{array}{l}\text { How did you find the transition from being a } \\
\text { medical student to being a member of staff? }\end{array}$ \\
\hline 4. & $\begin{array}{l}\text { How did you cope emotionally with the } \\
\text { experience? }\end{array}$ \\
\hline 5. & $\begin{array}{l}\text { What did you find challenging? What did you } \\
\text { find beneficial? }\end{array}$ \\
\hline 6. & What did you learn from this experience? \\
\hline 7. & $\begin{array}{l}\text { How did working in the ICU change your } \\
\text { perspective about the COVID-19 crisis? }\end{array}$ \\
\hline 8. & $\begin{array}{l}\text { Did working in the ICU change your decision } \\
\text { about your future medical specialty? }\end{array}$ \\
\hline
\end{tabular}

ICU, intensive care unit.

for medical students, with a view to assessing how volunteering may have developed components which would otherwise be difficult to teach directly in the curriculum.
The authors also wished to further explore the degree to which volunteering during the COVID-19 pandemic impacted medical student lives at home. ${ }^{18-20}$ The questions were kept open-ended to increase the quality of the data collected. Data were collected from 27 August 2020 to 29 October 2020 using the reflection prompts outlined in table 1 .

\section{DATA ANALYSIS}

The experiences of the respondents were analysed retrospectively. Transcripts were uploaded on NVivo V.12 (QSR International, Cheshire, UK) for coding and analysis. Transcripts were coded by topics defined by RCSI's main themes of medical professionalism (figure 1). Additional nodes were added on NVivo when additional relevant information was found in the data in terms of building medical students' aspects of medical professionalism. Coding was made on the 13 transcripts that were collected according to three emerging main themes of the volunteering experience: professional and emotional development, future career prospects and working in a

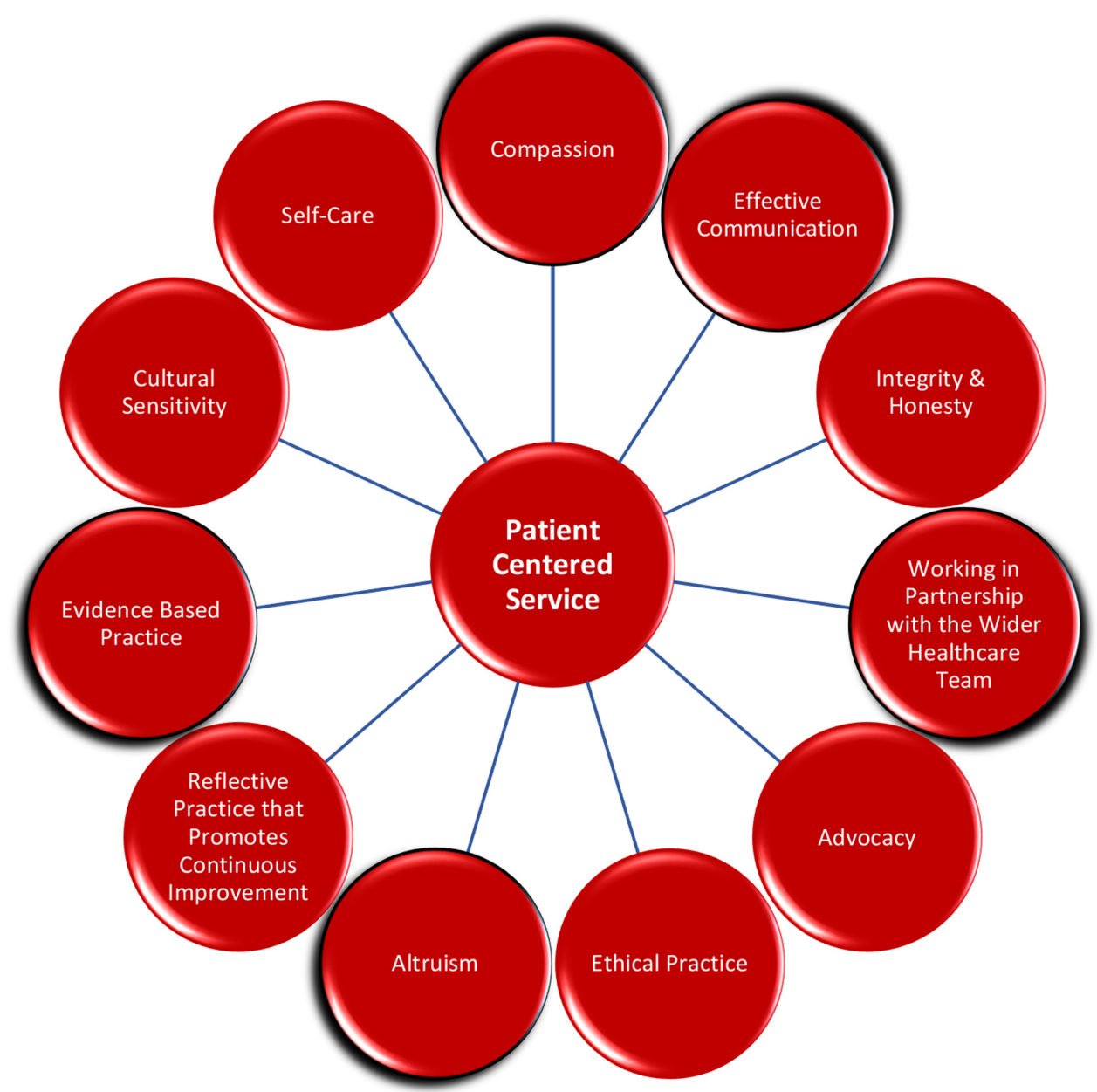

Figure 1 Evidence-based practice, partnership, communication, compassion and altruism identified as major areas of professional development. The figure depicts Royal College of Surgeons in Ireland (RCSI)'s definition of medical professionalism with major themes identified in student reflections. 
hospital environment. Two of the authors independently coded the transcripts and collated their findings.

\section{RESULTS}

\section{Demographics}

All 26 students who had volunteered were invited to participate in the survey, of whom 13 responded. Ten students were between 18 and 30 years old and three students were older. Seven respondents were female and six were male. Eleven responses were from students on the graduate entry medicine programme and two responses were from students on the undergraduate entry medicine programme. Four students were in their first year, nine students had completed first year, but had not commenced the clinical years. All of the respondents would have had limited clinical exposure through their course prior to engaging in volunteering during COVID-19.

\section{Professional and emotional development}

The study aimed to analyse the students' professional development within the context of RCSI's definition of medical professionalism (figure 1). Nine out of 11 skills were quoted by participants. The most prominent themes from the RCSI's definition of professionalism that emerged are highlighted in figure 1, the three main themes being working with a multidisciplinary team (MDT), effective communication and compassion. The most quoted areas are summarised in table 2, illustrated with sample student quotations.

While some of the participants reported no effect on their emotional development, many students described the volunteering experience as inflicting emotional strain on their lives for multiple reasons. The most prominent were: dealing with illness and death, witnessing patient isolation and the stressful work environment. These are illustrated best by the following quotations:

"The biggest thing that affected me was realising the vulnerability of the patients. Firstly, I had never spent a significant time in the ICU, so at times I was upset about how ill the patients truly were. It was difficult to see the patients every day, and then one day learning they had passed in the night."

"Dealing with others and communicating in a high stress environment wasn't something I had encountered in this way before where the stakes were so high."

".... due to COVID, there were no visitors allowed in the ICU. This meant many people were dying alone, and their loved ones couldn't say their goodbyes."

Students reported that this experience built their resilience to face future challenges and these students viewed resilience as a component of help for their future careers.

"Regarding resilience, this showed me that I can adapt to a new challenge, even if it is frightening, and make myself useful and productive."

Table 2 Quotations illustrating areas of development from RCSI's definition of professional development

Skill developed
Working in partnership with the wider healthcare team

Effective communication

Compassion

Altruism

Evidence-based practice

Self-care

\section{Sample quotations}

"Working in Partnership-This was perhaps the biggest take away from the proning experience. Seeing anaesthetists, nurses, porters, and members of other healthcare teams interacting every day to ensure the safety and care of the patients was inspiring." "I feel that I better understand how the wider healthcare team interacted in the hospital/ ICU during the pandemic peak."

"Effective communication between team members was vital."

"Proning requires good coordination and timing, and that could be achieved only with effective communication."

"Compassion: This was something we were always considerate of as a proning team and sometimes were able to remind other doctors of their need to maintain this during the procedure."

"Altruism was certainly a large part of the proning experience as it would not really have been possible to partake in the proning for any reason other than to help and care for others."

"'Altruism'. We risked our own health coming to the hospital to help the medical staff and patients."

"During the COVID-19 pandemic, new information was published on a daily basis, it was thus crucial for us to keep up with the latest evidence for our practice." "I learned the importance of evidence-based practice and the role it plays in guiding the treatment of patients. Due to the novelty of the virus, there was a lack of solid evidence which appeared to be an obstacle faced when treating the COVID-19 patients."

"It was a highly emotional experience, and quite overwhelming emotionally at times. As mentioned earlier, it was very important to keep self-care at the top of the list each day when I got home and to take the time to either write down my thoughts/experiences from the day or to discuss them with friends/family." 
The support of family and team members was reported as key to staying resilient.

"The support of family members and other team members helped with coping, and in that way I stayed resilient despite the pressure and intensity of the environment."

\section{FUTURE CAREER PROSPECTS \\ Critical care work}

Some students reported wanting to work in critical care after the proning experience. One student was deterred from critical care work after the experience. Other specialities considered by students as a result of their experience were public health, anaesthesiology, respiratory medicine and emergency medicine.

\section{Perceived attributes of a good physician}

Several participants identified in their reflections important attributes of physicians that they observed during their proning experience that they envisage applying in their future careers. Those include compassion, good communication with family members, fearlessness, goal-driven work ethic and hard work.

\section{EMERGING THEMES \\ Motivation}

The study also highlighted what motivates medical students to volunteer, and whether this motivation originates from the medical curriculum. The three most common reasons for volunteering were found to be a 'sense of duty' instilled by medical education, a 'desire to help' the country's effort and a desire to help the global effort to fight the pandemic.

\section{Effect of proning on students' lives}

Finally, it was found that while some students reported no change in their day-to-day lives, more than half of the respondents made special arrangements in order to both volunteer and protect their family members. Notably, some participants moved to a different accommodation while volunteering. The rest lived with their parents but maintained a social distance within the household, which was sometimes reported as mentally challenging.

\section{Discussion}

The reflections in this study document the growth of individual medical students, both professionally and personally, as a result of their experience of volunteering during the COVID-19 pandemic. Most students who volunteered had limited clinical exposure and no experience of being in an ICU. Understanding the challenges and benefits to students is important to identify how students can be supported and what learning can provide critical insights into how a unique opportunity such as this can shape their professional and emotional development. ${ }^{15} 1720$ This information can be key to identify what supports are required and how volunteering can be beneficial in medical student training.

Medical schools have different values that they aim to develop in their graduates. The RCSI definition of medical professionalism is one that all medical graduates are expected to incorporate into their practice. The definition is focused on patient-centred care and includes 11 distinct skills (figure 1). Some of these attributes are hard to develop through the formal teaching programme. It has been previously discussed that these values are instilled as a part of the 'hidden curriculum'. ${ }^{30}$ This is based on learning by both straightforward and challenging experiences and requires the student to be immersed in the environment from which they are implicitly learning. Volunteering on the proning team provided an opportunity for students to hone some of these skills. Students report 9 of the 11 skills to have been practiced during their experience.

The most quoted skill in the students' reflective pieces was the importance of working in partnership with the wider healthcare team. The results of a recent study from Poland found that one of the benefits of medical students volunteering during the COVID-19 pandemic was gaining professional experience which would prepare them for their future careers as doctors. ${ }^{31}$ Respondents in this current study frequently commented that working as a member of the MDT gave them a remarkable insight into the roles of different members of the team and how these integrate to promote patient-centred care. There was a notable mention of the roles of nurses, healthcare assistants and porters-members of the team with which students might otherwise have had limited interaction. Similar results have been reported regarding medical students' experiences volunteering in the UK. ${ }^{32}$ Doctors and nurses have previously been identified as role models for medical students on clinical placement, ${ }^{33}$ but participants in this study reported that seeing the work not only of doctors and nurses, but also of other members of the MDT such as healthcare assistants and porters was 'inspiring'.

The second most important competence identified was effective communication. Students reported communication was vital to deliver safe care. A breakdown in communication is a well-defined contributor to medical errors. In the USA, medical error has been reported as the third leading cause of death, with communication breakdown being a major contributor. ${ }^{34}$

Effective communication and conflict management are crucial within the ICU environment. These skills largely depend on an individual's ability to sense different personalities and relationships and provide another challenge for the 'hidden curriculum' to try to catch. ${ }^{35}$

Students reported how they learnt not only from practising good communication but also from witnessing examples of bad communication. Experiencing how things went wrong when there was a breakdown in communication was a memorable learning experience for some. This highlights the necessity for students to be 
directly involved in patient care in order to gain experience communicating with members of the healthcare team.

Compassion was the third most quoted skill. Compassion, as a skill, alongside training in the areas of humanism and communication, has long been emphasised as a vital need in the training of physicians. ${ }^{36}$ Witnessing severe illness and experiencing what it feels like to lose a patient allowed some students to develop compassion. Interestingly, one student noted that being in the ICU blunted their compassion. In situations where there is a lack of interaction between the patients and the healthcare providers, it might be challenging to build a bond with the patient and to feel compassion and have empathy. Students are taught about the importance of always maintaining a compassionate approach to the care of a patient. However, it should be highlighted how difficult this can be when the patient is sedated and unable to communicate as some of the students learnt from this experience. In contrast to the findings of this study, another study from the $\mathrm{UK}^{37}$ found medical students were concerned by practical measures such as the availability of personal protective equipment. This did not arise as a concern among the participants of this current study where students' main concerns were in relation to emotional strain while working with critically ill patients.

Students volunteering as part of this initiative faced unexpected challenges and development outside of RCSI's definition of medical professionalism. Although learning about death and dying are formal components of the curriculum, it is reasonable to say that the most valuable learning with respect to this is achieved by experiencing the death of a patient in whose care one is involved. An important learning point is for medical students to recognise death as a part of life rather than a traumatic event. ${ }^{38}$ Some respondents found themselves experiencing death and dying during this volunteering programme and found this difficult to cope with. One person remarked how using the support of family members and other team members helped them to stay resilient. This is not something that can be easily taught formally and therefore greater emphasis on exposing medical students to the care of dying patients should be considered.

This work also promoted students' emotional development while challenging their resilience. Literature supporting the existence of psychological supports for healthcare workers, particularly during a global pandemic, is sparse; and psychological outcomes following the SARS-CoV-1 epidemic has affected nearly one quarter of doctors. This has manifested as severe emotional distress in many. ${ }^{39}$ It has also been noted that the hospital environment, irrespective of the level of contact with infected patients, contributes significantly to distress. ${ }^{2440}$ However, the primary emotional challenge that participants faced was coping with the patients' severity of illness and seeing their families dealing with it. Many respondents found it challenging or upsetting to be involved in the care of critically ill patients and many felt nervous and emotionally unprepared before the experience; yet they felt that the volunteering prepared them for future emotionally demanding situations. It is interesting to note how the participants linked exposure to the high stress environment with their emotional development. This is another outcome of the medical curriculum that is difficult to formally teach and may highlight the importance and benefit of supporting students through emotionally challenging clinical experiences.

At a time of global uncertainty, volunteers were able to put aside their own needs in order to help in the Irish response to COVID-19 despite the emotional strain they experienced. Some participants made personal sacrifices when signing up to volunteer, notably organising special living arrangements in order to protect their families and this was a source of psychological strain for some. One of the aims of the RCSI's curriculum is to encourage medical students to practice self-care in order to shape their resilience to prepare them for the demands of their future careers. Some participants reported using selfcare to alleviate the mental burden of working in the ICU, while one reported the negative impact that a lack of self-care had on their mental health. Interestingly, this same participant mentioned that they felt their resilience did not develop. In contrast, the other respondents grew from this experience. These insights highlight the importance of actively practising self-care and may encourage medical educators to emphasise its significance and to formally incorporate it into the medical curriculum.

This volunteering experience has helped students gain a better appreciation and understanding of the roles of allied health professionals working in the MDT. They gained this appreciation by working within a defined role alongside other members of the MDT. Understanding the role of each member of the MDT is essential for the team to work safely and efficiently. It has been shown that the integration of medical students into the MDT enhances their experience while on clinical placement as well as having the added benefit of improving patient safety. ${ }^{41}$ Medical education may be improved on by better defining the role of the medical student as part of the wider medical team. ${ }^{35}$

This unique experience has had an impact on the professional identity development of the participants. While working in the ICU, students observed some important attributes of a good physician such as adaptability, effective communication, compassion and a goal-driven work ethic. It has previously been shown that experiences in medical school are likely to influence career choices. ${ }^{42} 43$ Some students remarked that the experience reinforced their desire to work in critical care. Others came to the realisation that the ICU setting was not suited to them. The variety of perspectives from different students in the same setting is interesting. In contrast, a study from China found that medical students' experience volunteering during the pandemic had no influence on their future career choices. ${ }^{44}$ During the 2009 swine influenza 
pandemic, the Royal Medical Academy of Belgium found that $91 \%$ of medical students felt that $\mathrm{H} 5 \mathrm{~N} 1$ patient care should be incorporated into the curriculum; and indeed this could be a strong consideration for the COVID-19 pandemic also. ${ }^{45}$ Being exposed to and working in different settings is important for making informed career choices. The medical curriculum affords this opportunity but arguably not to the same extent as working as key members of the medical team in the context of a global pandemic.

\section{STUDY LIMITATIONS}

The cohort of students was limited to early stage medical students at one medical school. The study was relatively small and focused. Also, the students were also volunteering in the ICU with a very specific role to assist in proning of patients with COVID-19. Therefore, these results provide insight into early stage medical students working in the ICU, and thus may not be generalisable to other volunteering roles or student cohorts.

While there were constraints due to the pandemic, increasing the sample range may have allowed for the identification of further themes and skills used among the students. The response rate was $50 \%$ which could have also introduced some non-responder bias. Additionally, prior to this study, there was limited literature relating to medical student experiences. The focus on the RCSI definition of professionalism components (figure 1) is likely to have biased respondents towards these factors; however, we were interested in these specific areas of development. There are many factors that affect medical student responses. ${ }^{18}$ To mitigate this, data were collected anonymously in the hope of collecting uninhibited responses. To increase generalisability, future studies should encompass students from both clinical years and preclinical years from multiple universities.

\section{CONCLUSIONS AND IMPLICATIONS}

This study highlights the challenges and benefits to early stage medical students volunteering in critical care during a pandemic. Significant development was identified in areas of professionalism, resilience and professional identity formation. The most common areas of professional development were as follows: working in partnership with the wider healthcare team, effective communication, evidence-based medicine, altruism and compassion. Development in these areas can be difficult to achieve through the formal curriculum, and therefore this was an extremely valuable learning experience for most students. Some respondents, however, found the experience extremely challenging and therefore supports should be in place prior to the implementation of such programmes to ensure that students are appropriately supported.

Volunteering in this environment had further effects on student's career choice with many students, suggesting that they would now consider critical care, anaesthesiology, respiratory medicine and emergency medicine.

Twitter Marian Brennan @marianbrennan

Acknowledgements The authors would like to thank the medical students who took part in this study for their time and reflections.

Contributors $A A, M S, A Q, G T, A H, S S$ and $M B$ contributed to the study concept and design. $A A, M S, A Q, G T$ and $M B$ contributed to data acquisition. $A A, M S, A Q, G T, P K$, $\mathrm{MB}$ and SS contributed to analysis and interpretation of data. All authors contributed to drafting of the manuscript. MB is the guarantor for the study.

Funding The authors have not declared a specific grant for this research from any funding agency in the public, commercial or not-for-profit sectors.

Competing interests None declared.

Patient and public involvement Patients and/or the public were not involved in the design, or conduct, or reporting or dissemination plans of this research.

Patient consent for publication Not applicable.

Ethics approval Ethical approval was obtained from the RCSI Human Research Ethics Committee (HREC) (REC202007002).

Provenance and peer review Not commissioned; externally peer reviewed.

Data availability statement Data are available upon reasonable request. Data are available on reasonable request from the study authors subject to ethical approval for its use.

Open access This is an open access article distributed in accordance with the Creative Commons Attribution Non Commercial (CC BY-NC 4.0) license, which permits others to distribute, remix, adapt, build upon this work non-commercially, and license their derivative works on different terms, provided the original work is properly cited, appropriate credit is given, any changes made indicated, and the use is non-commercial. See: http://creativecommons.org/licenses/by-nc/4.0/.

ORCID iD

Marian Brennan http://orcid.org/0000-0003-2368-5383

\section{REFERENCES}

1 Statement from The National Public Health Emergency Team. [press release]. Ireland: Department of Health, 2020.

2 West JB. The physiological challenges of the 1952 Copenhagen poliomyelitis epidemic and a renaissance in clinical respiratory physiology. J Appl Physiol 2005;99:424-32.

3 Kadlece J. Medical students determined to help during WTC tragedy. Columbia News 2001.

4 Starr I. Influenza in 1918: recollections of the epidemic in Philadelphia. Ann Intern Med 1976;85:516-8.

5 March S. Medical students urged to volunteer as NHS winter crisis worsens. The Guardian 2018.

6 Carson S, Peraza LR, Pucci M, et al. Student Hotline improves remote clinical skills and access to rural care. PRiMER 2020;4:22.

7 Glikman DM, Aviv L.;, Cohen G.;. K. Volunteer activity by medical students during the initial phases of covid-19. BMJ 2020.

8 Kinder F, Harvey A. Covid-19: the medical students responding to the pandemic. BMJ 2020;369:m2160.

9 Soled D, Goel S, Barry D, et al. Medical student mobilization during a crisis: lessons from a COVID-19 medical student response team. Acad Med 2020;95:1384-7.

10 Rasmussen S, Sperling P, Poulsen MS, et al. Medical students for health-care staff shortages during the COVID-19 pandemic. Lancet 2020;395:e79-80.

11 Herman B, Rosychuk RJ, Bailey T, et al. Medical students and pandemic influenza. Emerg Infect Dis 2007;13:1781-3.

12 AlOmar RS, AIShamlan NA, AlAmer NA, et al. What are the barriers and facilitators of volunteering among healthcare students during the COVID-19 pandemic? A Saudi-based cross-sectional study. BMJ Open 2021;11:e042910.

13 Drexler R, Hambrecht JM, Oldhafer KJ. Involvement of medical students during the coronavirus disease 2019 pandemic: a crosssectional survey study. Cureus 2020;12:e10147.

14 Gouda P, Kirk A, Sweeney A-M, et al. Attitudes of medical students toward Volunteering in emergency situations. Disaster Med Public Health Prep 2020;14:308-11. 
15 Tempski P, Arantes-Costa FM, Kobayasi R, et al. Medical students' perceptions and motivations during the COVID-19 pandemic. PLoS One 2021;16:e0248627.

16 Lazarus G, Findyartini A, Putera AM, et al. Willingness to volunteer and readiness to practice of undergraduate medical students during the COVID-19 pandemic: a cross-sectional survey in Indonesia. BMC Med Educ 2021;21:138.

17 Adams JG, Walls RM. Supporting the health care workforce during the COVID-19 global epidemic. JAMA 2020;323:1439-40.

18 Astorp MS, Sørensen GVB, Rasmussen S, et al. Support for mobilising medical students to join the COVID-19 pandemic emergency healthcare workforce: a cross-sectional questionnaire survey. BMJ Open 2020;10:e039082.

19 Banjar WM, Alaqeel MK. Healthcare worker's mental health dilemma during COVID-19 pandemic: a reflection on the KSA experience. $J$ Taibah Univ Med Sci 2020;15:255-7.

20 Klasen JM, Meienberg A, Nickel C, et al. SWAB team instead of SWAT team: medical students as a frontline force during the COVID-19 pandemic. Med Educ 2020;54:860.

21 Heath C, Sommerfield A, von Ungern-Sternberg BS. Resilience strategies to manage psychological distress among healthcare workers during the COVID-19 pandemic: a narrative review. Anaesthesia 2020;75:1364-71.

22 Chan AOM, Huak CY. Psychological impact of the 2003 severe acute respiratory syndrome outbreak on health care workers in a medium size regional General Hospital in Singapore. Occup Med 2004;54:190-6.

23 Maunder RG, Lancee WJ, Balderson KE, et al. Longterm psychological and occupational effects of providing hospital healthcare during SARS outbreak. Emerg Infect Dis 2006;12:1924-32.

24 Maunder RG, Leszcz M, Savage D, et al. Applying the lessons of SARS to pandemic influenza: an evidence-based approach to mitigating the stress experienced by healthcare workers. Can $J$ Public Health 2008;99:486-8.

25 Byrnes YM, Civantos AM, Go BC, et al. Effect of the COVID-19 pandemic on medical student career perceptions: a national survey study. Med Educ Online 2020;25:1798088.

26 Gallagher TH, Schleyer AM. "We Signed Up for This!" - Student and Trainee Responses to the Covid-19 Pandemic. N Engl J Med 2020;382:e96.

27 Lin C-Y, Peng Y-C, Wu Y-H, et al. The psychological effect of severe acute respiratory syndrome on emergency department staff. Emerg Med J 2007;24:12-17.

28 Phua DH, Tang HK, Tham KY. Coping responses of emergency physicians and nurses to the 2003 severe acute respiratory syndrome outbreak. Acad Emerg Med 2005;12:322-8.

29 Chawłowska E, Staszewski R, Lipiak A, et al. Student Volunteering as a solution for undergraduate health professions education: lessons from the COVID-19 pandemic. Front Public Health 2020;8:633888.
30 Gofton W, Regehr G. What we don't know we are teaching: unveiling the hidden curriculum. Clin Orthop Relat Res 2006;449:20-7.

31 Bazan D, Nowicki M, Rzymski P. Medical students as the volunteer workforce during the COVID-19 pandemic: Polish experience. Int $J$ Disaster Risk Reduct 2021;55:102109.

32 Buckland R. Medical student volunteering during COVID-19: lessons for future interprofessional practice. $J$ Interprof Care 2020;34:679-81.

33 Greenstock L, Brooks P, Malloy E, et al. Medical students' perceptions of role models on clinical placements. Clin Teach 2014;11:104-8.

34 Makary MA, Daniel M. Medical error-the third leading cause of death in the US. BMJ 2016;353:i2139.

35 Fassier T, Azoulay E. Conflicts and communication gaps in the intensive care unit. Curr Opin Crit Care 2010;16:654-65.

36 Wilkes M, Milgrom E, Hoffman JR. Towards more empathic medical students: a medical student hospitalization experience. Med Educ 2002;36:528-33.

37 Patel J, Robbins T, Randeva $\mathrm{H}$, et al. Rising to the challenge: qualitative assessment of medical student perceptions responding to the COVID-19 pandemic. Clin Med 2020;20:e244-7.

38 Smith-Han K, Martyn H, Barrett A, et al. That's not what you expect to do as a doctor, you know, you don't expect your patients to die." Death as a learning experience for undergraduate medical students. BMC Med Educ 2016;16:108.

39 Raurell-Torredà M, Martínez-Estalella G, Frade-Mera MJ, et al. Reflections arising from the COVID-19 pandemic. Enferm Intensiva 2020;31:90-3.

40 Soto-Rubio A, Giménez-Espert MDC, Prado-Gascó V. Effect of emotional intelligence and psychosocial risks on burnout, job satisfaction, and nurses' health during the COVID-19 pandemic. Int $J$ Environ Res Public Health 2020;17. doi:10.3390/ijerph17217998. [Epub ahead of print: 3010 2020].

41 Fox $\mathrm{L}$. The benefits of including medical students in the ward huddle. Med Teach 2021;43:721-2.

42 Are C, Stoddard HA, Nelson KL, et al. The influence of medical school on career choice: a longitudinal study of students' attitudes toward a career in general surgery. Am J Surg 2018;216:1215-22.

43 Woolf K, Elton C, Newport M. The specialty choices of graduates from Brighton and Sussex medical school: a longitudinal cohort study. BMC Med Educ 2015;15:46.

44 Zhang K, Peng Y, Zhang X, et al. Psychological burden and experiences following exposure to COVID-19: a qualitative and quantitative study of Chinese medical student volunteers. Int $J$ Environ Res Public Health 2021;18. doi:10.3390/ijerph18084089. [Epub ahead of print: 1304 2021].

45 Mortelmans LJM, De Cauwer HG, Van Dyck E, et al. Are Belgian senior medical students ready to deliver basic medical care in case of a H5N1 pandemic? Prehosp Disaster Med 2009;24:438-42. 